\title{
GESTÃO DE RELACIONAMENTOS PELOS PROFISSIONAIS DA CONTABILIDADE: ANÁLISE DA CAPTAÇÃO E MANUTENÇÃO DE CLIENTES NO CONTEXTO BRASILEIRO
}

\author{
RELATIONSHIP MANAGEMENT BY ACCOUNTING PROFESSIONALS: ANALYSIS \\ OF ATTRACTING AND MAINTAINING CUSTOMERS IN THE BRAZILIAN CONTEXT
}

\author{
Jenifer Cristina Silva ${ }^{1}$ \\ Centro Universitário Estácio de Sá \\ jenifercristina15@gmail.com
}

\author{
Igor Pereira da Luz \\ Centro Universitário Estácio de Sá \\ Universidade Federal de Santa Catarina \\ i.pereiradaluz@gmail.com
}

\author{
Rodrigo Rengel \\ Universidade Federal de Santa Catarina (UFSC) \\ rengel.rodrigo@hotmail.com
}

\section{RESUMO}

A pesquisa possui como objetivo evidenciar quais práticas são realizadas pelos profissionais contábeis para obtenção e manutenção de novos clientes. Para isto, realizou-se uma pesquisa descritiva, tipo levantamento survey, e de abordagem quantitativa. A amostra final totalizou 165 respondentes. Os dados obtidos foram analisados por estatística descritiva. Os resultados revelam que os contadores utilizam algumas práticas de marketing para auxiliar na captação de novos clientes, porém ainda não fazem o uso total dessa ferramenta a seu favor. Os achados ainda apresentam que a qualidade dos serviços prestados é primordial para a permanência dos clientes no portfólio dos prestadores de serviços contábeis. Entretanto, estes serviços de qualidade não apresentam tamanha necessidade aos clientes a ponto de estarem dispostos a pagarem qualquer quantia. Por fim, esta pesquisa contrasta achados de estudos anteriores que relatam preocupação dos contadores quanto sua imagem, ao demonstrar a falta de utilização de técnicas para aquisição/manutenção de clientes.

Palavras-chave: Contadores. Serviços contábeis. Captação de clientes. Manutenção de clientes. Gestão de Relacionamento.

\footnotetext{
${ }^{1}$ Endereço: Rua Leoberto Leal, 431, Barreiros, São José, Santa Catarina CEP 88117001
} 


\section{ABSTRACT}

The research aims to evidence which practices are performed by accounting professionals to obtain and maintain new customers. For this, a descriptive research was carried out, such as a survey, and a quantitative approach. The final sample totaled 165 respondents. The data obtained were analyzed using descriptive statistics. The results reveal that accountants use some marketing practices to help attract new customers, but they still do not make full use of this tool in their favor. The findings also show that the quality of the services provided is essential for the permanence of customers in the portfolio of accounting service providers. However, these quality services do not present such a need to customers that they are willing to pay any amount. Finally, this research contrasts findings from previous studies that report accountants' concern about their image, by demonstrating the lack of use of techniques for acquiring / maintaining customers.

Keywords: Accountants. Accounting services. Customer acquisition. Customer maintenance. relationship management.

\section{INTRODUÇÃO}

O número de profissionais atuantes na área da contabilidade tem crescido consideravelmente no Brasil. O fato é explicado diante da contabilidade apresentar uma vasta gama de possibilidades no mercado de trabalho e atuação em várias vertentes (Tamer, Viana, Soares \& Lima, 2013). A evolução tecnológica e sua utilização nos serviços contábeis modificou a atuação deste profissional. Diante disso, o contador necessita se atualizar constantemente e diferenciar sua atuação junto às organizações com as quais operam. Assim um novo perfil desse profissional e novas oportunidades de negócios originaram-se (Lima \& Gomes Filho, 2019; Santos, Carvalho, Maia, Souza \& Visentin, 2019).

Conforme Pereira (2002), as organizações evoluíram e necessitam de seus profissionais conhecimentos além dos específicos de sua área de atuação. Qualidades como autoestima, boa comunicação, bom humor, e capacidade de liderança são exemplos destas necessidades para que se tenha um profissional intelectualizado, apto e capaz de desempenhar com excelência suas atividades. Por este motivo, apresenta-se uma tendência de investir no marketing pessoal, contábil e trabalhar na imagem deste profissional. Pesquisas têm demonstrado a evolução dessa preocupação pelo profissional contábil (Dimnik \& Felton, 2006; Peleias, Hernandes, Garcia \& Silva, 2007), visando um desenvolvimento de seu marketing pessoal.

Para Ritossa (2009), o marketing pessoal é o conjunto de ações planejadas que facilitam a obtenção de sucesso pessoal e profissional, seja para conquistar uma nova posição no mercado de trabalho ou para manter sua posição atual. Essas ações compreendem não só a divulgação de uma melhor imagem, mas também o aprimoramento de deficiências e o investimento em atributos. Ou seja, significa destacar a imagem do "produto" que é chamar a atenção de novos clientes da maneira certa. Segundo Kotler (2000), a retenção de clientes exige habilidades substanciais em geração de indicações, qualificação de indicações e conversão dos clientes potenciais. As empresas que querem aumentar sua carteira de clientes precisam investir tempo e recursos para conseguir alcançar esses objetivos.

Neste sentido, elaborou-se o seguinte problema de pesquisa: Quais práticas são realizadas pelos profissionais contábeis para captação e manutenção de novos clientes? Destarte, o objetivo de pesquisa é evidenciar quais práticas são realizadas pelos profissionais contábeis para obtenção e manutenção de novos clientes. Para cumprir o objetivo proposto foi realizada uma pesquisa survey com os contadores registrados no Conselho Regional de Contabilidade de Santa Catarina (CRC/SC) e mais 947 escritórios contábeis do Brasil, obtendo um total de 165 respostas válidas. Os achados apontam para a utilização de algumas práticas de 
marketing pelos contadores para auxiliar na captação de novos clientes e na atenção na qualidade dos serviços.

Justifica-se a importância do presente estudo, pois possíveis melhorias na forma de relacionamentos com os clientes pode auxiliar no atendimento as novas demandas exigidas. Tal fato é ainda mais relevante para os contadores atuantes que desejam alcançar o sucesso almejado e se manterem competitivos no mercado. Nessa conjuntura, o estudo contribuí com uma visão dos profissionais sobre ferramentas de desenvolvimento profissional, como o marketing pessoal e contábil, com vistas a se destacar e valorizar-se perante os clientes. No mais, há poucos estudos em marketing que focam especificamente em empresas de contabilidade (Santos et al., 2019), logo, justifica-se sua originalidade e apresenta sua contribuição teórica. Por fim, têm-se como contribuição social a apresentação das informações obtidas por meio deste estudo, que podem contribuir para todos os profissionais contábeis, acadêmicos do curso de ciências contábeis, empresas privadas, clientes finais e profissionais atuantes na área de marketing.

O restante deste artigo está estruturado da seguinte forma: além da presente introdução, é apresentada, na seção 2, o referencial teórico do estudo dividido em Marketing, Captação e manutenção de clientes e Evolução da profissão contábil e suas tendências; os procedimentos metodológicos aparecem na seção 3; na seção 4, são apresentados os resultados do estudos divididos em: Caracterização dos respondentes, Análise da captação dos clientes, Análise da permanência dos clientes e Análise da qualidade dos serviços; as considerações finais estão na seção 5; e, por fim, são apresentadas as referências utilizadas no presente estudo.

\section{REFERENCIAL TEÓRICO}

\subsection{Marketing}

Marketing pode ser entendido por Kotler (1998) como o processo social e gerencial por meio do qual indivíduos e grupos obtêm aquilo que necessitam, criando e trocando produtos e valores uns com os outros. Ou ainda, trabalhar com mercados para realizar trocas potenciais com o propósito de satisfazer necessidades e desejos humanos. Marketing é um conjunto de atividades cujo objetivo é levar bens e serviços do produtor ao consumidor (Moreira, Pasquale \& Dubner, 1999). No caso das empresas prestadoras de serviço, tal como os escritórios de contabilidade, destaca-se a necessidade de refletir sobre os aspectos importantes do marketing que podem ser relevantes para os serviços profissionais e estimular as empresas a revisar e analisar suas presunções a este respeito acerca de tomar medidas para aperfeiçoamento do seu desempenho (Kotler, 2002).

Organizações e pessoas se utilizam desta ferramenta para agregarem valor ao seu produto ou serviço ofertado, pois independentemente do tamanho de uma empresa, deve procurar desenvolver um bom marketing. Torna-se vital a criação de uma marca referência que esteja sempre nas preferências dos consumidores, isto é fundamental para a sobrevivência organizacional (Prado, 2017). Com a expansão da internet e o surgimento de um novo perfil de consumidor, surgiu a necessidade de investimentos em estratégias de marketing online com a finalidade de facilitar o contato permanente e interativo entre empresa e consumidor. As redes sociais, por exemplo, são consideradas eficazes ao serem utilizadas como fonte de informação (Silva, Silva \& Prado, 2015). Esse advento da era da informação traz novas perspectivas, desafios e oportunidades para as organizações (Vaz, 2010).

Neste contexto surge o marketing digital, que representa uma ferramenta extremamente competitiva, pois abrange diversas possibilidades de divulgação e crescimento para as organizações, promovendo produtos, serviços ou a própria marca por meio da internet. Utilizando a internet como ferramenta de marketing é possível ampliar mercado, promover mais 
negócios, interagir em tempo real com os consumidores de forma rápida, personalizada e eficiente (Ryan \& Jones, 2012; Silva et al., 2015).

Por esta razão torna-se necessário o entendimento da utilidade do marketing digital e pessoal para a vida profissional preparando-o para desempenhar suas funções básicas e para absorver o máximo de conhecimento possível para melhor atender os clientes (Laurindo, 2004). A discussão sobre a aplicabilidade do marketing pessoal aos profissionais da área contábil requer a definição e o estudo do termo. Com base em Nogueira (2001), o marketing pessoal é a capacidade de criar vantagens competitivas, e dar visibilidade adequada às próprias competências, visando o reconhecimento, ou seja, a capacidade que o profissional tem de acreditar no próprio sucesso. Para Drucker (1995), a meta é conhecer e compreender tão bem o cliente que o produto ou serviço se adapte a ele e se venda por si só.

\subsection{Captação e manutenção de clientes}

Saber como chamar a atenção do cliente é de suma importância para o sucesso de qualquer negócio. Hoffman e Bateson (2003) citam que uma das principais estratégias da comunicação de serviços é informar, persuadir e lembrar os clientes sobre o serviço que está sendo oferecido. Os autores (2003) ainda identificam o "mix de mercado" como um canal direto com os potenciais clientes. Basicamente esse mix é um conjunto de ferramentas usadas pelos profissionais de marketing com o intuito de promover a comunicação mais adequada para transmitir a mensagem do negócio, entre as principais estão: a venda pessoal, a propaganda, a mala direta e a mais utilizada ainda, comunicação "boca a boca".

Lovelock e Wirtz (2008) complementam que contatos por telefone e outras formas de comunicação, como e-mail e sites web, podem surtir efeito e proliferar a mensagem do negócio mais ágil e facilmente, e que estas estratégias devem ser usadas não só na captação de novos clientes, mas na fidelização dos já existentes. É de extrema importância que as empresas desenvolvam formas para atrair e reter seus clientes. As ferramentas do marketing de relacionamento podem ser utilizadas para atingir esse objetivo, uma vez que ajudam a manter os clientes satisfeitos, gerando benefícios tanto para os clientes quanto para a empresa (Magalhães, Crnkovic \& Moretti, 2009).

Uma empresa prestadora de serviços, além de possuir o domínio de todo o processo de oferta do produto, deve se atentar a interação com os seus clientes, esta questão define a percepção de qualidade nos serviços prestados pelos consumidores. Um atendimento mal sucedido pode acarretar danos irreversíveis ao relacionamento. O serviço de qualidade pode trazer clientes e lucros mais altos porque as pessoas estão dispostas a pagar mais para ter um bom tratamento. Para atender bem os clientes, é necessário ter uma estrutura formal adequada para ter, além de rapidez nas suas decisões, qualidade nos demais setores de suporte (Silveira, Domaresk \& Kato, 2007).

\subsection{Evolução da profissão contábil e suas tendências}

A maneira de atuação e as necessidades dos contabilistas têm se alterado com o passar dos anos, o que acaba por expandir seu campo de habilidades, não se limitando apenas ao conhecimento técnico contábil, mas também a um nível de cultura geral que permita o entendimento do ambiente econômico, político e social em que os usuários de informações estão inseridos, tal evidência requer destes profissionais maior familiaridade com questões envolvidas aos negócios (Ott \& Pires, 2008).

Com isso, tornam-se relevantes as discussões relacionadas à caracterização e à adequação no perfil do contador, de maneira que ele esteja efetivamente preparado para atender as exigências pertinentes às suas atividades profissionais. Essa relevância é reconhecida por diversos pesquisadores que têm tratado do tema, a exemplo de Consenza (2001), Cardozo, 
Souza e Almeida (2006), Ribeiro (2007), Peleias, Guimarães, Silva e Ornelas (2008). Para os autores, o contador moderno deve dominar todas as competências e habilidades que permeiam a profissão, porém, de forma contextualizada e com visão nas diversas relações com outras áreas de conhecimento; além disso, ele também deve ser visto como um comunicador de informações essenciais à tomada de decisões.

Para Tocha (2017), o marketing tem recebido um maior destaque pelos profissionais contábeis, um tema relativamente novo no Brasil. Apesar do termo marketing ser empregado há anos, sua aplicabilidade na contabilidade ainda é recente. Poucos empresários contábeis sabem como, de fato, adaptar o marketing a seus negócios. Sabendo da dificuldade que muitos profissionais da área sentem na hora de divulgar sua marca, captar novos clientes, engajar antigos e, por conseguinte crescer.

Pensando a este respeito, Cobra (1995) já era visionário sobre o posicionamento da marca que é a arte de configurar a imagem de uma empresa ou instituição num dado segmento de mercado, de forma que os consumidores pudessem entender e apreciar o que o produto, a empresa ou instituição proporciona. No caso da Contabilidade, pode-se entender que ela é a "marca" de uma instituição formada por um corpo de conhecimentos próprios.

Percebe-se que as transformações ocorridas na contabilidade ao longo dos anos exigiram do profissional contábil sua adaptação a um novo cenário. Os novos profissionais serão forçados a expandir suas habilidades para além dos números, mudando a forma como tratam os problemas, passando a considerá-los para além das fronteiras nacionais. O profissional que o mercado anseia deverá dedicar-se muito mais para decisões e previsões futuras do que para a história ou passado (Ott \& Pires, 2008).

A esse respeito, é preciso considerar que o profissional contábil vem sendo preparado para lidar com a tecnologia da informação que se desenvolve rapidamente, capaz de compreender a complexidade das transações de negócios que ocorrem interna e externamente às empresas, para a correta mensuração do patrimônio e seu resultado, e se manter informado sobre as mudanças que ocorrem em sua profissão nos aspectos normativos e legais que influenciam nas atividades econômicas das entidades sob sua responsabilidade (Tobias \& Nascimento, 2010).

Um estudo realizado por Hiroshi (1998) já evidenciava a necessidade de mostrar ao público em geral a nova realidade da Contabilidade, e demonstrar a importância das ferramentas de Marketing para a Contabilidade. Nesse trabalho, o autor ressaltou a importância de se ter um posicionamento para a marca "Contabilidade", e propôs um plano de marketing para obtenção do devido reconhecimento por ele mencionado. Estudo reforçado por Peleias, Hernandes, Garcia e Silva (2007), Dias e Santos Filho (2015) e Morais e Souza (2015) que destacaram a necessidade de ampliar os estudos sobre marketing em empresas de contabilidade, por ser esse um serviço técnico, especializado, e relevante para a sociedade.

Scarpin, Scarpin e Calijuri (2000) chamaram a atenção para "valorização profissional por meio do uso dos instrumentos de marketing". Em seu estudo, os autores identificaram a ausência no uso desse recurso pelos profissionais contábeis. Para Laurindo (2004), embora o termo marketing contábil seja uma ideia nova, percebeu-se, inclusive, certa resistência para sua inserção no meio empresarial, o contador moderno assim como seus clientes apresentam-se cada vez mais flexíveis às mudanças. Mais recentemente, Lima e Gomes Filho (2019), ao analisar contadores da cidade de Icó no Estado do Ceará, encontraram que os contadores apresentam um nível satisfatório de conhecimento sobre o marketing, sendo que, sua orientação está em geral correlacionada a promoção e divulgação dos produtos e serviços, e, nos processos de satisfação dos clientes, no modo presencial e virtual.

A melhoria da qualidade dos serviços de contabilidade deve estar continuamente nos planos dos empresários para manter sua carta de clientes. Nesse contexto, Dias Filho e Santos (2013) concordam que dentre as principais contribuições do marketing para a profissão e para 
as empresas prestadoras de serviços de contabilidade está na busca incessante da satisfação dos usuários do serviço, que é diretamente ligada à qualidade do serviço, levando à retenção e fidelização do cliente.

\section{PROCEDIMENTOS METODOLÓGICOS}

Este estudo caracteriza-se como uma pesquisa descritiva, pois descreve as características de determinada população ou fenômeno. Uma de suas peculiaridades está na utilização de técnicas padronizadas de coleta de dados, tais como o questionário e a observação sistemática (Gil, 2008). A abordagem é quantitativa e quanto ao procedimento técnico é caracterizado como um levantamento, tipo survey (Gil, 2008).

A população da pesquisa é composta por todos os contadores registrados no Conselho Regional de Contabilidade de Santa Catarina (CRC/SC) e mais 947 escritórios contábeis do Brasil. A coleta de dados foi realizada por meio de questionários do Google Forms. O CRC/SC disparou este para todos os contadores registrados: foram enviados 18.549 mensagens, entregues 18.289, mensagens abertas 2.397, mensagens com links acessados 205, mensagens não abertas 15.892 , mensagens com links não acessados 18.084 , mensagens não entregues 260 , além dos 947 e-mails enviados para escritórios contábeis localizados em todo o Brasil para participar desta pesquisa. A amostra totalizou 165 respondentes. A Tabela 1 apresenta o instrumento de pesquisa.

Tabela 1. Questionário de Pesquisa

\begin{tabular}{|c|c|c|c|}
\hline \multirow{7}{*}{$\begin{array}{l}\text { Captação } \\
\text { dos clientes }\end{array}$} & \multicolumn{2}{|l|}{ Como os clientes são conquistados? } & Mensuração \\
\hline & \multicolumn{2}{|l|}{ Conhecem os sócios. } & \multirow{6}{*}{$\begin{array}{l}\text { Sim ou Não para } \\
\text { todas assertivas }\end{array}$} \\
\hline & \multicolumn{2}{|l|}{ Os advogados de nossos clientes têm nos indicado. } & \\
\hline & \multicolumn{2}{|l|}{ Empresas de auditoria têm nos indicado. } & \\
\hline & \multicolumn{2}{|l|}{ Funcionários de antigos clientes têm nos indicado. } & \\
\hline & \multicolumn{2}{|c|}{$\begin{array}{l}\text { A boa reputação entre os clientes tem contribuído para conquistar novos } \\
\text { clientes. }\end{array}$} & \\
\hline & \multicolumn{2}{|c|}{$\begin{array}{l}\text { A localização do escritório é um fator importante na conquista, } \\
\text { manutenção e relacionamento. }\end{array}$} & \\
\hline \multirow{7}{*}{$\begin{array}{l}\text { Manutenção } \\
\text { dos clientes }\end{array}$} & \multicolumn{2}{|l|}{ A permanência dos clientes depende de: } & Mens \\
\hline & Serviço prestado. & PER1 & \multirow{6}{*}{$\begin{array}{c}\text { Escala Likert de } 5 \\
\text { pontos - De } \\
\text { Discordo } \\
\text { Plenamente a } \\
\text { Concordo } \\
\text { Plenamente }\end{array}$} \\
\hline & A capacitação das pessoas responsáveis pelas atividades. & PER2 & \\
\hline & Conhecimento dos profissionais. & PER3 & \\
\hline & $\begin{array}{l}\text { Todas as pessoas envolvidas na prestação de serviços devem } \\
\text { conhecer profundamente suas atividades e responsabilidades. }\end{array}$ & PER4 & \\
\hline & Atender o cliente no tempo é fundamental. & PER5 & \\
\hline & Atendê-lo no padrão de qualidade esperado pelo cliente. & PER6 & \\
\hline \multirow{7}{*}{$\begin{array}{l}\text { Qualidade } \\
\text { dos Serviços }\end{array}$} & Qualidade dos serviços prestados: & & Men: \\
\hline & $\begin{array}{l}\text { O cliente quer serviços de qualidade, independente dos } \\
\text { horários. }\end{array}$ & QUA1 & \multirow{6}{*}{$\begin{array}{c}\text { Escala Likert de } 5 \\
\text { pontos - De } \\
\text { Discordo } \\
\text { Plenamente a } \\
\text { Concordo } \\
\text { Plenamente }\end{array}$} \\
\hline & $\begin{array}{l}\text { O serviço mal feito causa retrabalho, custos adicionais e } \\
\text { reflexos negativos junto ao cliente. }\end{array}$ & QUA2 & \\
\hline & O cliente paga mais quando o serviço atende suas exigências. & QUA3 & \\
\hline & $\begin{array}{l}\text { O retrabalho impede que o tempo consumido seja usado para } \\
\text { atender melhor o próprio cliente afetado, e impede o } \\
\text { atendimento a outros clientes. }\end{array}$ & QUA4 & \\
\hline & $\begin{array}{l}\text { A maioria dos clientes que perdemos foram empresas que } \\
\text { fecharam ou se mudaram. }\end{array}$ & QUA5 & \\
\hline & A relação com os clientes é estritamente profissional. & QUA6 & \\
\hline
\end{tabular}

Fonte: Elaborado pelos autores.

A primeira etapa do questionário caracteriza o perfil dos respondentes. Já o segundo 
bloco identifica de que maneira os contadores conquistam seus novos clientes e de quais mídias sociais ou meios se utilizam para fazer isto. O terceiro bloco evidencia como os clientes são mantidos. E, por fim, no quarto bloco é enfatizado a qualidade dos serviços prestados. Todos baseados nas percepções dos contadores. As questões que compõem estes blocos foram extraídas do estudo de Peleias et al. (2007) e adaptado conforme o foco desta pesquisa para uma melhor compreensão das informações apresentadas, e assim alcançar a resposta para a problemática investigada.

A pesquisa em si está sujeita a uma variedade de limitações, que vão desde o problema desenvolvido, aos critérios de seleção e o tipo de amostragem adotado (por acessibilidade), até mesmo a interpretação do pesquisador. Faz-se necessário esclarecer que as interpretações de população e amostra não são fixas.

\section{APRESENTAÇÃO E ANÁLISE DOS DADOS}

\subsection{Caracterização dos respondentes}

A pesquisa primeiramente realizou a análise descritiva dos respondentes, contando com 165 respostas recebidas. A Tabela 2 apresenta a análise do gênero e idade dos respondentes.

Tabela 2. Gênero e Idade dos respondentes

\begin{tabular}{|c|c|c|c|}
\hline Variável & Níveis da Variável & $N^{0}$ de Respondentes & \% de Respondentes \\
\hline \multirow{3}{*}{ Gênero } & Feminino & 67 & $40,6 \%$ \\
\hline & Masculino & 98 & $59,4 \%$ \\
\hline & TOTAL & 165 & $100 \%$ \\
\hline \multirow{5}{*}{ Idade } & Até a 30 anos & 52 & $31,5 \%$ \\
\hline & De 31 a 40 anos & 45 & $27,3 \%$ \\
\hline & De 41 a 50 anos & 32 & $19,4 \%$ \\
\hline & A partir de 51 anos ou mais & 36 & $21,8 \%$ \\
\hline & TOTAL & 165 & $100 \%$ \\
\hline \multirow{5}{*}{$\begin{array}{l}\text { Tempo de } \\
\text { atuação }\end{array}$} & Até 10 anos & 90 & $54,5 \%$ \\
\hline & De 11 a 20 anos & 36 & $21,8 \%$ \\
\hline & De 21 a 30 anos & 15 & $9,1 \%$ \\
\hline & Acima de 31 anos & 24 & $14,6 \%$ \\
\hline & TOTAL & 165 & $100 \%$ \\
\hline
\end{tabular}

Fonte: Dados da Pesquisa (2020).

A faixa etária dos respondentes obteve uma variação expressiva, pois contou com respostas de 21 até os 78 anos de idade, sendo a maior representatividade entre os respondentes acima de 31 anos. Entretanto, a faixa com maior número de respondentes foi até os 30 anos $(31,5 \%)$. Notou-se que a amostra é composta em maior número por contadores homens $(59,4 \%)$.

Também foi possível identificar, na Tabela 2, o demonstrativo de quanto tempo, aproximadamente, os respondentes atuam no mercado, demonstrando que 54,3\% atua de 1 a 10 anos; $22 \%$ atua entre 11 anos e 20 anos; os demais atuam a mais de 21 anos. Os dados demonstram que a maioria dos respondentes tem menos de dez anos de mercado, que pode ser explicado pela crescente da profissão. Buscou-se ainda as funções dos contadores respondentes. A partir dos dados obtidos, foi possível destacar os cargos ou funções que atuam, somente as mais citadas foram destacadas na Tabela 3. 
Tabela 3. Cargos ou Funções dos respondentes

\begin{tabular}{l|l|c}
\hline \multicolumn{2}{c|}{} & \multicolumn{1}{c}{ FA } \\
\hline \multirow{4}{*}{ Cargos ou Funções } & Analista contábil / Analista Fiscal & 18 \\
\cline { 2 - 3 } & Assistente contábil / Auxiliar contábil & 17 \\
\cline { 2 - 3 } & CEO & 4 \\
\cline { 2 - 3 } & Consultor(a) & 56 \\
\cline { 2 - 3 } & Contador(a) & 4 \\
\cline { 2 - 3 } & Coordenador(a) & 9 \\
\cline { 2 - 3 } & Diretor(a) & 4 \\
\cline { 2 - 3 } & Empresário(a) & 8 \\
\cline { 2 - 3 } & Gerente & 5 \\
\cline { 2 - 3 } & Proprietário(a) & 19 \\
\cline { 2 - 3 } & Sócio(a) & 17 \\
\cline { 2 - 3 } & Demais funções citadas & $\mathbf{1 6 5}$ \\
\hline
\end{tabular}

Legenda: $\mathrm{FA}=$ Frequência Absoluta

Fonte: Dados da Pesquisa (2020).

Tem-se com os achados apresentados na Tabela 3 um portfólio vasto de atividades exercidas pelos profissionais da área contábil, que atuam desde diretorias executivas até cargos de auxiliares. Destaca-se ainda que a amostra conta com profissionais assalariados e empreendedores evidenciando a variedade de caminhos que a atividade contábil proporciona, tendo a maioria dos respondentes apontado a função de contador sem especificar o nível e/ou o foco de atuação.

\subsection{Análise da captação dos clientes}

Para análise das assertivas apresentadas na Tabela 4, envolvendo a forma de captação de novos clientes, foi realizado uma análise descritiva, a partir das respostas encontradas. Entre as estratégias utilizadas para a conquista de clientes a maioria dos respondentes apontaram apenas que a boa reputação entre os clientes tem contribuído para conquistar novos clientes, com 51 dos respondentes apontando apenas para essa alternativa na conquista de clientes. Este fator evidencia que a maioria aposta apenas nesta alternativa e não utiliza outros meios ou formas para captação de novos clientes. Nesta etapa da pesquisa era permitido escolher mais de uma alternativa, dado este que representa a não utilização de mais de uma maneira para captação de novos clientes, pois aposta-se muito ainda no bom relacionamento e boa reputação praticada com os clientes atuais para atraírem novos consumidores.

Tabela 4. Assertivas derivadas das respostas da questão: Como os clientes são conquistados?

\begin{tabular}{l|l|c|c}
\hline Constructo & \multicolumn{1}{|c|}{ Assertivas } & FA & FR \\
\hline \multirow{5}{*}{$\begin{array}{c}\text { Conquista } \\
\text { dos Clientes }\end{array}$} & Os clientes já conhecem os sócios. & 73 & 24,8 \\
\cline { 2 - 4 } & Os advogados de nossos clientes têm nos indicado. & 18 & 6,1 \\
\cline { 2 - 4 } & Empresas de auditoria têm nos indicado. & 2 & 0,7 \\
\cline { 2 - 4 } & $\begin{array}{l}\text { Auncionários de antigos clientes têm nos indiciado. } \\
\text { clientes. }\end{array}$ & 18 & 6,1 \\
\cline { 2 - 4 } & $\begin{array}{l}\text { A localização do escritório é um fator importante na conquista, } \\
\text { manutenção e relacionamento. }\end{array}$ & 34,2 \\
\cline { 2 - 4 } & Nenhuma das Alternativas & 22 & 11,6 \\
\hline
\end{tabular}

Legenda: FA = Frequência Absoluta; FR = Frequência Relativa

Fonte: Dados da Pesquisa (2020).

Outro fator importante é que muitos dos clientes já conhecem os sócios aumentando a clientela com maior facilidade, mas também prejudicando o uso de alternativas mais eficazes. 
Os contadores precisam explorar todos os meios disponíveis para a obtenção de novos clientes, não se limitando apenas ao uso de um meio ou outro.

Pelos dados apresentados as empresas de auditoria deixaram de indicar os serviços contábeis. É possível supor que tal fato ocorra, pois muitas empresas atualmente também fornecem serviços contábeis, sendo assim, são concorrentes dos contadores e escritórios contábeis. Percebe-se, ainda, que os contadores dependem de indicações e de um bom relacionamento com os atuais clientes para a conquista de novos, demonstrando que o dito "boca a boca" ainda é muito utilizado.

Os resultados encontrados corroboram o estudo de Peleias et al. (2007) que encontrou que a maioria dos clientes são conquistados pois os sócios já os conheciam e as indicações por boa reputação. Destaca-se que mesmo após dez anos do estudo realizados não foram encontradas evoluções para a captação do cliente, o que se infere uma estagnação dos contadores nesse quesito.

\subsection{Análise da permanência dos clientes}

A análise das estratégias foi feita por meio da estatística descritiva, para melhor compreensão e identificação dos dados obtidos com a assertiva para demonstrar do que depende a permanência dos clientes. A Tabela 5 apresenta os resultados referentes a permanência dos clientes.

Tabela 5. Análise descritiva das assertivas de Permanência dos clientes

\begin{tabular}{c|l|c|c|c|c|c|c|c}
\hline Constructo & Quest & Min & Max & Média & Med & Moda & DP & CV \\
\hline \multirow{4}{*}{$\begin{array}{c}\text { Permanência } \\
\text { dos Clientes }\end{array}$} & PER1 & 1 & 5 & 4,570 & 5 & 5 & 0,766 & $16,76 \%$ \\
\cline { 2 - 9 } & PER2 & 1 & 5 & 4.406 & 5 & 5 & 0,803 & $18,23 \%$ \\
\cline { 2 - 9 } & PER3 & 1 & 5 & 4,430 & 5 & 5 & 0,813 & $18,35 \%$ \\
\cline { 2 - 9 } & PER4 & 1 & 5 & 4,285 & 4 & 5 & 0,882 & $20,58 \%$ \\
\cline { 2 - 9 } & PER5 & 1 & 5 & 4,467 & 5 & 5 & 0,808 & $18,09 \%$ \\
\cline { 2 - 8 } & PER6 & 2 & 5 & 4,491 & 5 & 5 & 0,677 & $15,07 \%$ \\
\hline
\end{tabular}

Legenda: Min = Mínimo; Max = Máximo; Med = Mediana; DP = Desvio Padrão; CV = Coeficiente de Variação. Fonte: Dados da Pesquisa (2020).

Quanto aos motivos para a permanência dos clientes, destaca-se que a média próxima a cinco para as assertivas e a consistência das respostas dos contadores, denotando a consciência deles para a permanência dos clientes. Entre as assertivas, tem-se a maior média para os serviços prestados, inferindo que para a manutenção dos clientes a boa prestação de serviços é parte fundamental. Corroborado pela assertiva PER6, que aponta que o padrão de qualidade é fundamental no atendimento ao cliente.

Quanto a todas as pessoas envolvidas na prestação de serviços devem conhecer profundamente suas atividades e responsabilidades, teve-se a menor média e menor consistência. Destaca-se que boa parte dos escritórios ainda trabalha na forma de departamentos, tem-se ainda que alguns funcionários fazem apenas serviços operacionais, o que não faz que eles tenham total conhecimento das operações, o que é uma possível explicação para os dados encontrados.

Dentre as alternativas, os respondentes concordam que prestar atendimento aos clientes em tempo hábil é fundamental para garantir a permanência dos mesmos, pois atender o consumidor com excelência não é mais um diferencial a ser oferecido, mas sim um diferencial no mercado. A permanência dos clientes revela um consenso no qual os contadores têm conhecimento que prestar serviço de qualidade, atendimento no prazo adequado e pessoal qualificado é de extrema importância, pois isto assegura a satisfação dos usuários dos serviços contábeis. Os resultados vão ao encontro dos achados de Lima e Gomes Filho (2019) e Santos et al. (2019) que apontam que os contadores utilizam tais estratégias para fortalecimento de 
vínculo com os clientes e no crescimento e consolidação do escritório no mercado local.

\subsection{Análise da qualidade dos serviços}

A análise das assertivas envolvendo a qualidade dos serviços prestados busca destacar de que maneira os contadores priorizam e de que forma identificam como os seus serviços são realizados. Os resultados são apresentados na Tabela 6.

Tabela 6. Análise descritiva das assertivas da Qualidade dos Serviços

\begin{tabular}{c|c|c|c|c|c|c|c|c}
\hline Constructo & Quest & Min & Max & Média & Med & Moda & DP & CV \\
\hline \multirow{3}{*}{$\begin{array}{c}\text { Qualidade } \\
\text { dos }\end{array}$} & QUA1 & 1 & 5 & 3,824 & 4 & 5 & 1,136 & $29,71 \%$ \\
\cline { 2 - 9 } & QUA2 & 1 & 5 & 4,564 & 5 & 5 & 0,656 & $14,37 \%$ \\
\cline { 2 - 9 } & QUA3 & 1 & 5 & 3,394 & 4 & 4 & 1,238 & $36,48 \%$ \\
\cline { 2 - 9 } & QUA4 & 2 & 5 & 4,364 & 4 & 5 & 0,749 & $17,16 \%$ \\
\cline { 2 - 9 } & QUA5 & 1 & 5 & 3,461 & 5 & 5 & 1,062 & $30,68 \%$ \\
\cline { 2 - 9 } & QUA6 & 1 & 5 & 3,606 & 4 & 5 & 1,080 & $29,95 \%$ \\
\hline
\end{tabular}

Legenda: Min = Mínimo; Max = Máximo; Med = Mediana; DP = Desvio Padrão; CV = Coeficiente de Variação. Fonte: Dados da Pesquisa (2020).

Nota-se as assertivas relacionadas a qualidade dos serviços apresentaram uma consistência menor que as assertivas relacionadas à permanência dos clientes, o que indica um problema, visto que não têm um consenso sobre a qualidade dos serviços prestados na contabilidade. Destaca-se a assertiva QUA4, que teve uma grande média e alta consistência, que trata sobre o retrabalho realizado nos escritórios e que impede que o tempo seja utilizado para atender melhor o próprio cliente, e ainda impede o atendimento a outros clientes.

A assertiva QUA2 corrobora com o indicativo, visto que os contadores tiveram uma maior média para a questão que o serviço mal feito causa retrabalho, custos adicionais e reflexos negativos junto ao cliente. Tem-se então uma concordância, do grande retrabalho nos serviços prestados de contabilidade, que abre uma lacuna para buscar melhorias que evitem esse retrabalho e melhor aproveitem os serviços contábeis.

Destaca-se ainda que a relação com os clientes não se restringe ao estritamente profissional, apontado pela média da assertiva QUA6, que corrobora com os achados de que uma parte significativa dos clientes é conquistada pois os sócios já eram conhecidos. O achado também corrobora o estudo de Peleias et al. (2007) e pode ser explicado pela captação de clientes, visto que boa parte dos clientes já conheciam os sócios, antes de utilizar seus serviços.

A qualidade dos serviços prestados indica uma média baixa para as alternativas: o cliente quer serviços de qualidade, independente dos honorários e o cliente não está disposto a pagar mais quando o serviço atende suas exigências, demonstra que os clientes não querem pagar mais pelos serviços contábeis, mesmo estes sendo de qualidade e os atendendo prontamente o que é considerado um problema para a classe de prestadores de serviços contábeis, visto que seus serviços não são valorizados pelo seu público, como apontado por Santos et al. (2019). Destaca-se que os resultados encontrados são preocupantes, evidenciando um retrocesso da profissão contábil, tendo que no estudo de Peleias et al. (2007) os contadores apontavam que os clientes buscavam serviços de qualidade independente dos honorários.

Os dados analisados apresentaram que a relação custo versus benefício é insuficiente merecendo atenção especial, pois ainda hoje o serviço contábil não detém o reconhecimento devido. Talvez por falta de habilidades dos próprios contadores em lidar com esta questão ou por não existir um órgão da classe que normatize valores mínimos a serem cobrados por tais serviços. 


\section{CONSIDERAÇÕES FINAIS}

Este artigo buscou evidenciar quais práticas são realizadas pelos profissionais contábeis para obtenção e manutenção de novos clientes. Para isto, aplicou-se um questionário com profissionais de contabilidade. Como amostra final, têm-se 165 contadores, das mais variadas áreas apresentando desde funções auxiliares até a presidência executiva de organizações, tendo a maioria se intitulada apenas como contadores.

Um dado de relevância indicativa é o exposto pelas assertivas de qualidade dos serviços prestados, os clientes demonstram certa resistência em pagar mais pelos serviços contábeis. Informação esta que causa muita preocupação, pois os usuários da contabilidade não dimensionam este serviço com a devida importância e valorização. Dado este que poderia ser modificado, pois os contadores têm o potencial e a visão do que é necessário para destacar suas competências e dar maior visibilidade ao seu serviço no mercado de trabalho.

Pode-se destacar, também, sobre o resultado apontado pelas assertivas como são conquistados novos clientes, mostra que os contadores ainda dependem de indicações de terceiros para que os seus serviços cheguem a novos clientes. Os achados evidenciam uma falta de evolução do marketing dos contadores na corroboração com o estudo de Peleias et al. (2007), visto que, mesmo após dez anos, os contadores ainda dependem de sua rede de contadores para a conquista de clientes.

Por fim, conclui-se que os contadores utilizam de alguns meios e alternativas de marketing pessoal no dia-a-dia para conquistar novos clientes, como a boa reputação com os clientes e a localização do escritório. No mais, os profissionais estão preocupados com a qualidade dos serviços prestados, investindo em pessoal qualificado e atentos com a questão do retrabalho. Todavia, destaca-se que os contadores ainda não exploram esta ferramenta diante de suas possibilidades, não acreditam que o marketing pessoal, contábil ou digital é aliado e que estas ferramentas auxiliam e agregam valor aos seus próprios serviços e capacidades. Os contadores têm conhecimento suficiente, além de serem portadores de informações primordiais, portanto investir em "sua marca" é fundamental e depende apenas dos próprios profissionais.

Uma sugestão para novas pesquisas, com abordagem similar a esta, é desenvolver estudos de caso que abordem os antecedentes e consequentes da utilização do marketing pessoal na carreira com os profissionais da área contábil que já o utilizam, para que os profissionais tenham ciência das possibilidades da utilização de tais estratégias.

\section{REFERÊNCIAS}

Bloom, P. N., Kotler, P., \& Hayes, T. (2002). Marketing de serviços profissionais. Editora Manole Ltda.

Cardoso, J. L., Souza, M. A., \& Almeida, L. B. (2006). Perfil do contador na atualidade: um estudo exploratório. Revista Base (Administração e Contabilidade) da UNISINOS, 3(3), 275-284.

Cobra, M. (1995). Plano estratégico de marketing. Atlas.

Cosenza, J. P. (2001). Perspectivas para a profissão contábil num mundo globalizado: um estudo a partir da experiência brasileira. Revista Brasileira de Contabilidade, 30(130), 4363.

Dias Filho, F. F., \& Santos, V. (2013). A percepção dos profissionais contábeis de Belo Horizonte sobre a utilidade do marketing de serviços para os escritórios de contabilidade. Revista Mineira de Contabilidade, 3(51), 16-23. 
Dimnik, T., \& Felton, S. (2006). Accountant stereotypes in movies distributed in North America in the twentieth century. Accounting, organizations and society, 31(2), 129-155.

Drucker, P. F. (1995). Administrando em tempos de grandes mudanças. Cengage Learning Editores.

Gil, A. C. (2002). Como elaborar projetos de pesquisa (Vol. 4, p. 175). São Paulo: Atlas.

Hiroshi, S. (1998). Um plano de marketing para a contabilidade. Caderno de Estudos, (17), 0116.

Hoffman, K. D., \& Bateson, J. E. (2003). Princípios de marketing de serviços. Pioneira Thompson Learning.

Kitchenham, B. A., \& Pfleeger, S. L. (2002). Principles of survey research part 2: designing a survey. ACM SIGSOFT Software Engineering Notes, 27(1), 18-20.

Kotler, P. (2000). Administração de marketing.

Laurindo, M. (2004). Marketing pessoal e o novo comportamento profissional. Ramalivros.

Lima, H. A., \& Gomes Filho, A. G. (2019). Marketing Contábil: um Estudo em Escritórios de Contabilidade do Município de Icó, Ceará-Brasil. ID on line Revista de Psicologia, 13(43), 62-75.

Lovelock, C. H., \& Wirtz, J. (2008). Marketing de serviços: pessoas, tecnologia e resultados. Pearson Prentice Hall.

Magalhães, M. D. R. A., Crnkovic, L. H., \& Moretti, S. A. (2009). Importância do Marketing de relacionamento para a melhoria do atendimento e da vantagem competitiva nos serviços médicos privados. Revista Brasileira de Marketing, 8(1), 70-92.

Morais, F. R., \& da Souza, W. S. (2015). A Importância do Marketing na Percepção de Estudantes de Graduação e Profissionais da Área Contábil. Revista Organizações em Contexto, 11(21), 73-100.

Moreira, J. C. T., Pasquale, P. P., \& Dubner, A. G. (2003). Dicionário de termos de marketing: definições, conceitos e palavras-chaves de marketing, propaganda, pesquisa, comercialização, comunicação e outras áreas correlatas a estas atividades Júlio César Tavares Moreira, Perrotti Pietrangelo Pasquale, Alan Gilbert Dubner. Atlas.

Nogueira, F. Marketing Pessoal: Conhecimento, Relacionamento, Estilo, Comunicação e Imagem. Edição CH-Consulting House. Fita de Vídeo.

Oliveira Reis, A., Sediyama, G. A. S., de Souza Moreira, V., \& Moreira, C. C. (2015). Perfil do profissional contábil: habilidades, competências e imagem simbólica. Revista Contemporânea de Contabilidade, 12(25), 95-116.

Ott, E., \& Pires, C. B. (2008). Um estudo sobre o Mercado de trabalho para contadores na região metropolitana de Porto Alegre-RS. Anais do Encontro da Anpad-EnAnpad, Rio de Janeiro, RJ, 32.

Peleias, I. R., Guimarães, P. C., Silva, D., \& Ornelas, M. M. G. (2008). Identificação do perfil profissiográfico do profissional de contabilidade requerido pelas empresas, em anúncios de emprego na região metropolitana de São Paulo. Revista Base (Administração e Contabilidade) da UNISINOS, 5(2), 131-141.

Peleias, I. R., Hernandes, D. C. R., Garcia, M. N., \& da Silva, D. (2007). Marketing contábil nos escritórios de contabilidade do Estado de São Paulo. Revista Brasileira de Gestão de Negócios-RBGN, 9(23), 61-77. 
Pereira, E. S., \& Leite Filho, G. A. (2015). A influência do marketing no perfil do profissional contábil. Pensar Contábil, 5(15).

Prado, A. (2017). Marketing pessoal e profissional: a importância da imagem. Recuperado de https://noticias.cancaonova.com/brasil/marketing-pessoal-e-profissional-importancia-daimagem>.

Ribeiro, M. A. (2007). O contador "profissional" e o contador "aplicado". Revista Eletrônica do CRCRS, Rio Grande do Sul, (05).

Ritossa, C. M. (2009). Marketing pessoal: quando o produto é você. Editora Ibpex.

Santos, E. S., Carvalho, N., Maia, S., Souza, F. M. A., \& Visentin, I. C. (2019). Estratégias de marketing no contexto da contabilidade. Humanidades e Tecnologia (FINOM), 16(1), 191228.

Scarpin, M. A., Scarpin, J. E., \& Calijuri, M. S. S. (2000). Marketing: Um instrumento para a valorização profissional. Anais de Congresso Brasileiro de Contabilidade, Goiânia, GO, Brasil, 16.

Silva, M. V. M., Silva, M. A., \& Prado, R. A. D. P. (2015). Marketing contábil: análise do uso das mídias sociais. Anais do Seminários em Administração - SEMEAD, São Paulo, SP, 18.

Silveira, A., Domareski, J. C., \& Kato, H. (2007). Aplicação do marketing de relacionamento em agências bancárias no estado de Santa Catarina. Revista de Negócios, 7(1).

Tamer, C., Viana, C., Soares, L. A., \& Lima, M. (2013). Perfil do profissional contábil demandado pelo mercado de trabalho: um estudo no norte do Brasil. Revista Universo Contábil, 9(3), 143-162.

Tobias, L. M. M., \& Nascimento, C. (2010). O perfil do profissional de Contabilidade à luz das demandas de mercado. Anais do Encontro Anual de Inscrição Científica, Ponta Grossa, PR, 19.

Tocha, R. (2017) Conquiste mais clientes com marketing contábil. Recuperado de https://www.nibo.com.br/wp-content/uploads/2017/10/GuiaConquiste-mais-clintes-como-markting-contabil-NIBO-1.pdf.

Vaz, C. A. (2009). Google Marketing-O Guia Definitivo de Marketing Digital. Novatec Editora. 